\title{
A Preliminary Analysis and Model of Prostate Injection Distributions
}

\author{
Scott L. Chowning, ${ }^{1 *}$ Robert C. Susil, ${ }^{1}$ Axel Krieger, ${ }^{3}$ Gabor Fichtinger, ${ }^{2,3,4}$ \\ Louis L. Whitcomb, ${ }^{3,4}$ and Ergin Atalar ${ }^{1,2,5}$ \\ 'Department of Biomedical Engineering, Johns Hopkins University School of Medicine, Baltimore, Maryland \\ ${ }^{2}$ Department of Radiology, Johns Hopkins University School of Medicine, Baltimore, Maryland \\ ${ }^{3}$ Department of Mechanical Engineering, Johns Hopkins University, Baltimore, Maryland \\ ${ }^{4}$ Department of Computer Science, Johns Hopkins University, Baltimore, Maryland \\ ${ }^{5}$ Department of Electrical and Electronics Engineering, Bilkent University, Ankara, Turkey
}

\begin{abstract}
PURPOSE. Understanding the internal dynamics of prostate injections, particularly injection pattern distribution is a key step to developing new therapies for prostate disease that may be best served with a direct injection approach. Due to excellent properties involving liquid contrast agents, MRI can be used for targeting and monitoring of injections into organs and tissues.

MATERIALS AND METHODS. Eleven intraprostatic injections were performed in vivo with canines using a custom transrectal guiding and imaging system for use in a standard $1.5 \mathrm{~T} \mathrm{MR}$ scanner. In addition, 25 injections were performed on excised cadaveric human prostates, using a MedRad Spectris ${ }^{\text {TM }}$ injector system. MRI was used to guide the injections and monitor intraparenchymal injection distribution.

RESULTS. T1 and T2-weighted MR images were correlated with histology to produce threedimensional data sets that can be used to analyze trends in injection patterns. This analysis was used to develop strategies for injection prediction such as gadolinium preinjections and diffusion-weighted imaging guidance. In addition, a rough model of prostate injections is described, and a preliminary injection guide is developed that takes into account the individual clinician's goals for therapy.

CONCLUSIONS. MR visualization of injected therapeutic agents allows for prediction and monitoring of drug distributions, possibly improving efficacy and reducing side effects. Injection analysis and modeling may be used to assist in optimizing clinical treatments that require or would benefit from focal parenchymal injections into the prostate. Prostate 66: 344-357, 2006.

(C) 2005 Wiley-Liss, Inc.
\end{abstract}

KEY WORDS: magnetic resonance imaging; prostate; injections; drug delivery systems

\section{INTRODUCTION}

There are a number of clinical treatments that involve direct intraparenchymal injection into various organs and tissues [1-4]. New treatments are being studied for prostate interventions, including injections for benign prostate hypertrophy (BPH) and prostate cancer [5]. Recently, such approaches have been studied using endorectal and transperineal routes, usually under ultrasound guidance, although MR is beginning to see use as a possible imaging method for prostatic injections [6]. In the case of $\mathrm{BPH}$, ethanol ablation has been studied as a possible therapy [7]. For prostate cancer applications, new treatment techniques are being developed which include immune system stimulation [8], viral [9,10], genetic [11], and radiosensitizing techniques [12]. While some treatment agents can

\footnotetext{
*Correspondence to: Scott L. Chowning, Department of Biomedical Engineering, Johns Hopkins University School of Medicine, 334 Traylor Building, 720 Rutland Avenue, Baltimore, MD 21205. E-mail: schowning@mri.jhu.edu

Received 3 May 2005; Accepted 4 May 2005

DOI 10.1002/pros.20298

Published online 21 November 2005 in Wiley InterScience (www.interscience.wiley.com).
} 
be applied via a systemic route, others require a maximum local concentration for effectiveness and therefore focal injection is desirable [13].

Despite the promise of local prostate injections, there are several complicating factors that so far have hindered widespread clinical usage. One problem in particular that has plagued local tissue injections is the faulty assumption that the chemical agent will be delivered to the same site at which it is injected. In addition, leakage is found to be a major problem with intraprostatic injections [6]. It is conceivable that many of these problems may be minimized through a better understanding of prostate injection distribution and probability of failure modes.

With this goal in mind, several imaging modalities have been used to guide and monitor injections, including ultrasound and magnetic resonance imaging. Although there are several other imaging methods for visualizing injected drug agents [14-16], MR is superior in terms of soft tissue contrast [17]. Contrast agents have been used previously for prostate imaging under trans-rectal ultrasound (TRUS) imaging guidance [18], and contrast-enhanced MR is used here as a tool to analyze, model, and predict liquid bulk flow inside the prostate. The goals of this study are: (1) Use a previously designed and described [6] MR-guided transrectal prostate injection and imaging system to analyze in vivo canine prostate injections; (2) compare/contrast prostate canine injection patterns with human prostate; (3) demonstrate accurate agent distribution confirmation via MR methods; (4) analyze leakage modes in the prostate; (5) show that tissue structure is a rough predictor of bulk flow inside the prostate; (6) develop a model for guiding prostate injection strategies.

\section{METHODS}

\section{Canine Injection Procedures}

An MR-guided, endorectal prostate imaging and injection system that allows for precise needle placement was employed for the canine portion of this study. This device was designed for canine trials and served as the prototype for a next-generation implementation in human trials [19]. All animal protocols were reviewed and approved by the Johns Hopkins Animal Care and Use Committee. The canines, each weighing approximately $25 \mathrm{~kg}$ were anesthetized with a bolus injection of thiopental and maintained on $1 \%$ isoflurane throughout the experiment. An IV catheter was placed in the right jugular vein for fluid administration and a Foley catheter was utilized to aid in stabilizing the prostate and to define the position of the prostatic urethra. The animals were placed prone on the scanner table with the pelvis slightly elevated $(\sim 10 \mathrm{~cm})$ with a 5 inch surface coil on the anterior surface of the abdomen at the level of the prostate. The rectal probe contains a single-loop endorectal imaging coil, and images were captured with contributions from both the endorectal coil and the 5 inch surface coil.

In the first canine, a $30 \mathrm{mM}$ solution of Gd-DTPA in normal saline was injected at eight sites within the prostate gland. Different volumes of contrast solution $(0.15,0.3$, or $0.6 \mathrm{ml})$ as well as different injection rates $(0.6-6 \mathrm{ml} / \mathrm{min})$ were utilized. In all cases except for one, injections were performed directly through the hollow 18-G canula. In one case, injections were performed though a 0.018-inch (26 G) diameter needle manufactured from nitinol hypotubing. Because these small-diameter hypotubing needles are so compliant, they were inserted into the tissue through the hollow canula (which was left in place) such that they emerged $3 \mathrm{~mm}$ past the canula tip. During injection, the flow of the contrast solution was monitored using a high flip-angle, RF-spoiled, gradient echo imaging sequence (FSPGR, TE $=1.5 \mathrm{msec}, \mathrm{TR}=6 \mathrm{msec}$, flip angle $=90^{\circ}$, $\mathrm{BW}=+/-62.5 \mathrm{KHz}, \mathrm{FOV}=16 \mathrm{~cm}$, no slice selection, $256 \times 160,0.96 \mathrm{sec} /$ image). The location of the injected solution was determined by comparing gradient echo axial images acquired both before and after the injection (FSPGR, TE $=2.0 \mathrm{msec}, \mathrm{TR}=80 \mathrm{msec}$, flip angle $=60^{\circ}, \mathrm{BW}=+/-31.25 \mathrm{kHz}, \mathrm{FOV}=16 \mathrm{~cm}$, slice thickness $=3 \mathrm{~mm}$, slice gap $=0.5 \mathrm{~mm}, 256 \times 256$, $\mathrm{NEX}=4$, scan time 1:20).

In the second canine, an iterative method for predicting the distribution of an injected therapeutic agent (here, ethanol) was considered. To detect potentially dangerous injections before the ethanol was introduced (i.e., those injections that could damage the urethra), test injections at each targeted site were performed using $0.1 \mathrm{ml}$ of $30 \mathrm{mM}$ gadolinium-DTPA in normal saline. All injections were performed through 0.018inch diameter nitinol needles. The distribution of this injected solution was visualized on T1-weighted images $(\mathrm{TE}=9.2 \mathrm{msec}, \mathrm{TR}=700 \mathrm{msec}, \mathrm{BW}=+$ / $-31.25 \mathrm{kHz}, \mathrm{ETL}=4, \mathrm{FOV}=16 \mathrm{~cm}$, slice thickness $=$ $3 \mathrm{~mm}$, slice gap $=0.5 \mathrm{~mm}, 256 \times 256, \mathrm{NEX}=4$, scan time $=3: 00$ ). Then, if the injection pattern was localized and did not involve the urethra, $0.2 \mathrm{ml}$ of dehydrated ethanol was injected for tissue ablation. Following the study and animal sacrifice, the prostate was removed, fixed in formalin, and sectioned axially such that tissue lesions could be correlated with the MR images.

\section{Human Injection Procedures}

A total of 13 fresh excised cadaveric human prostates were removed surgically from the anatomy lab at the Maryland State Anatomy Board with approval from the Johns Hopkins University School of Medicine Biosafety Officer and the Director of the Anatomy 
Board. Twelve of the prostates were kept in $0.9 \%$ isosaline solution and refrigerated for a maximum of $24 \mathrm{hr}$ before the imaging experiments. One prostate was immediately placed in a $10 \%$ formalin solution for $48 \mathrm{hr}$ to achieve fixation. $0.5 \mathrm{ml}$ of Gd-DTPA was added with $9.5 \mathrm{ml}$ of each of four dyes-black, blue, green, and red-to produce a 5\% Gd-DTPA-dye solution.

For each prostate, up to four injection sites were chosen, at different superior/inferior positions within the prostate and targeting different anatomical boundaries within it (transition zone (TZ), peripheral zone (PZ)). Since the human prostates were ex vivo, the injection needle was placed by hand, and position confirmed by T2 weighted MR. Each of the human prostates were positioned with the urethra colinear with the longitudinal axis of the MR bore, with the posterior portion of the gland facing upwards. This setup is close to the anatomical position of a patient laying prone in the MR scanner, which is the typical patient position for endorectal coil experiments in vivo.

In the first set of experiments, injections were performed on a formalin-fixed human prostate. To test the effect of chemical fixation on prostate injections, we injected three times into this fixed prostate at various anatomical positions. We observed the flow of contrast with MR guidance and then sectioned the gland for histology analysis. Another set of trials was aimed at analyzing leakage modes in the human prostate. Using a fixed volume and flow rate of $1 \mathrm{ml}$, and $0.1 \mathrm{ml} / \mathrm{sec}$, respectively, ten separate injections were performed. Of those ten injections, seven could be explicitly localized to either the TZ or PZ. The volume of contrast in the parenchyma, as well as contrast seen in the urethra or leakage out of the capsule was approximated on the MR images using a contour tool. The contour tool gives a measure of area covered, and then the total volume was calculated by summing the areas found across all the slices. We reported the numbers in terms of a percentage volume distribution (numbers rounded to nearest $10 \%$ ).

To get a better understanding of how flow rate and total volume affect injectant dispersion, we performed 16 injections and measured contrast dispersion with MR guidance. In the first trial, we kept the flow rate and total volume injected constant at $0.1 \mathrm{ml} / \mathrm{sec}$ and $1 \mathrm{ml}$ $(\mathrm{N}=8)$. In the second trial, we increased the total volume injected by $100 \%$ and held the flow rate constant $(\mathrm{N}=4)$. In a third trial, we kept the total volume injected constant and changed the flow rate from $0.1 \mathrm{ml} / \mathrm{sec}$ to $0.2 \mathrm{ml} / \mathrm{sec}(\mathrm{N}=4)$.

Before each injection, the following image sequences were acquired in all three planes: (1) T1 weighted RF-spoiled gradient echo (FSPGR, $\mathrm{TE}=2.8 \mathrm{msec}$, $\mathrm{TR}=85 \mathrm{msec}$, flip angle $=60^{\circ}, \mathrm{BW}=+/-31.25 \mathrm{kHz}$,
$\mathrm{FOV}=16 \mathrm{~cm}, 256 \times 256$, slice thickness $=3 \mathrm{~mm}$, slice gap $=0.5 \mathrm{~mm}, \mathrm{NEX}=4$, scan time $=2: 10)$; (2) $\mathrm{T} 2$ weighted fast spin echo (TE $=60 \mathrm{msec}$, $\mathrm{TR}=5500 \mathrm{msec}$, $\mathrm{BW}=+/-15.6 \mathrm{kHz}, \mathrm{ETL}=4, \mathrm{FOV}=16 \mathrm{~cm}, 256 \times 256$, slice thickness $=3 \mathrm{~mm}$, slice gap $=0.5 \mathrm{~mm}$, scan time $=$ 5:20); and (3) T2 Diffusion-weighted images using the General Electric ${ }^{\mathrm{TM}}$-developed DWI propeller sequence $(\mathrm{TE}=100 \mathrm{msec}, \mathrm{TR}=5,000 \mathrm{msec}, \mathrm{ETL}=16$, $\mathrm{b}=1,000 \mathrm{sec} / \mathrm{mm}^{2}, 256 \times 256$, slice thickness $=3 \mathrm{~mm}$, slice gap $=0 \mathrm{~mm}$, scan time $=7: 00$ ). The diffusion weighted images were postprocessed using a General Electric Signa $\mathrm{L} X^{\mathrm{TM}}$ console computer into three image sets including a baseline unweighted set, an apparent diffusion coefficient (ADC) map and an exponentially weighted ADC map. All diffusion-weighted images were acquired in the axial plane only. A standard General Electric ${ }^{\mathrm{TM}}$ head coil was used in all human prostate injection experiments. A MedRad Spectris MR Injection System ${ }^{\mathrm{TM}}$ was used for each injection (except the formalin fixed prostate experiments, see Results for reasoning/details). During the injection, a high flip angle RF-spoiled fast gradient echo sequence (FSPGR, $\mathrm{TE}=1.5 \mathrm{msec}, \mathrm{TR}=6 \mathrm{msec}$, flip angle $=90^{\circ}, \mathrm{BW}=+$ / $-62.5 \mathrm{kHz}, \mathrm{FOV}=16 \mathrm{~cm}, 256 \times 160,1 \mathrm{sec} /$ image) was used to monitor the real-time distribution of the injected contrast agent. Afterwards, the same T1 and T2 image sets described above were re-acquired to show pre-and post-contrast images. After each imaging experiment, the prostate was stored in $10 \%$ formalin solution for 3 days, after which it was removed and sliced into $3 \mathrm{~mm}$ axial sections for histology analysis.

\section{RESULTS}

\section{Single-Injection Distribution Patterns in Canine Prostate}

In the first canine, a series of eight transrectal intraprostatic needle placements and injections were performed. During each injection, a high-flip-angle, RF-spoiled, gradient-echo acquisition was run to visualize the agent's distribution. Dynamic images acquired during five of the injections are shown in Figs. 1-4. Each figure shows a sagittal scout along with individual frames from the time-series images. In the majority of cases, much of the solution does not stay within the tissue but rather, leaks into surrounding structures. In Figure 1, the solution tracks superiorly along the interface between the rectum and the prostate. Figure 2 shows a case where the solution gathered along the needle path, which is brightly enhanced by the end of the injection. In two cases, the injected solution stayed very concentrated within the tissue (as seen in Fig. 3). In Figure 4, the solution penetrated to the middle of the prostate and then tracked up the urethra towards the bladder. 

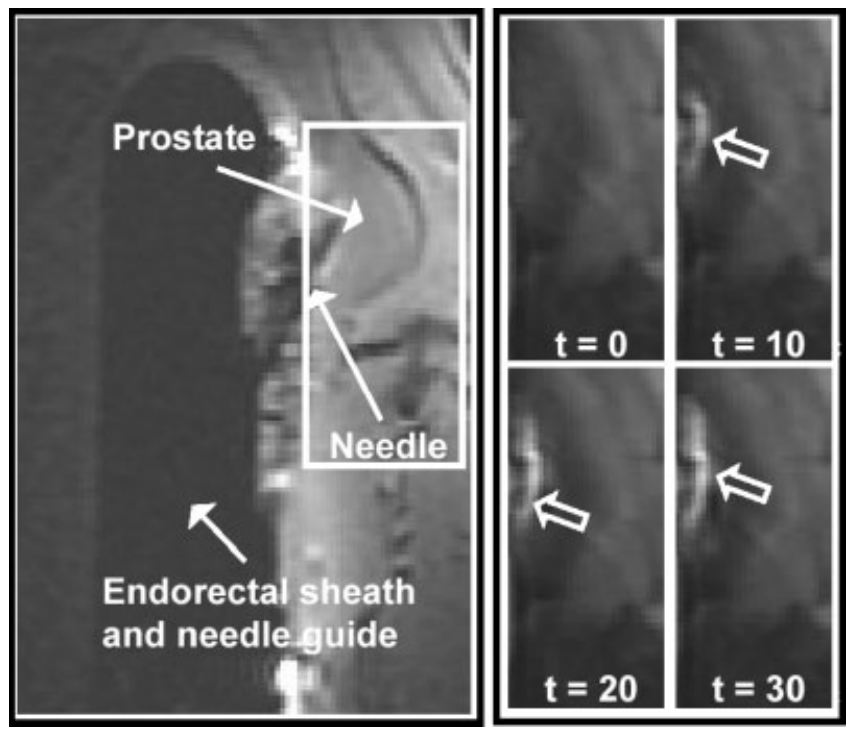

Fig. I. Canine Single-injection Trials: Injected contrast solution accumulating at the prostate-rectum interface. The white box in the sagital scout image (left panel) shows the location of the timeseries images (four right panels). $0.3 \mathrm{ml}$ of $30 \mathrm{mMGd}$-DTPA in normal saline was injected over $30 \mathrm{sec}$ through the $18-\mathrm{G}$ canula. The solution can be seen tracking superiorly along the prostate-rectum interface (open arrows). Times are given in seconds.

\section{Multiple-Injection Distribution Patterns in Canine Prostate}

As prostate cancer is often considered to be a multifocal disease, it may be desirable to deliver a
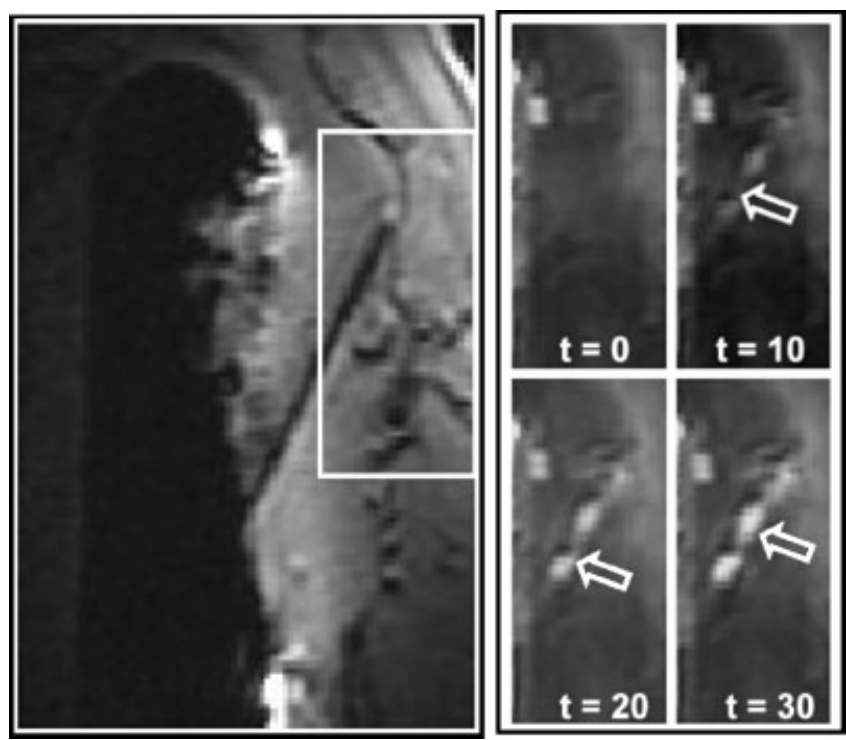

Fig. 2. Canine Single-Injection Trials: Injected contrast solution tracking along the needle path. $0.3 \mathrm{ml}$ of $30 \mathrm{mM}$ Gd-DTPA solution was injected over $30 \mathrm{sec}$ through the $18-\mathrm{G}$ canula. The majority of the solution is visible along the needle path (open arrows), rather than at the needle tip.Times are given in seconds.

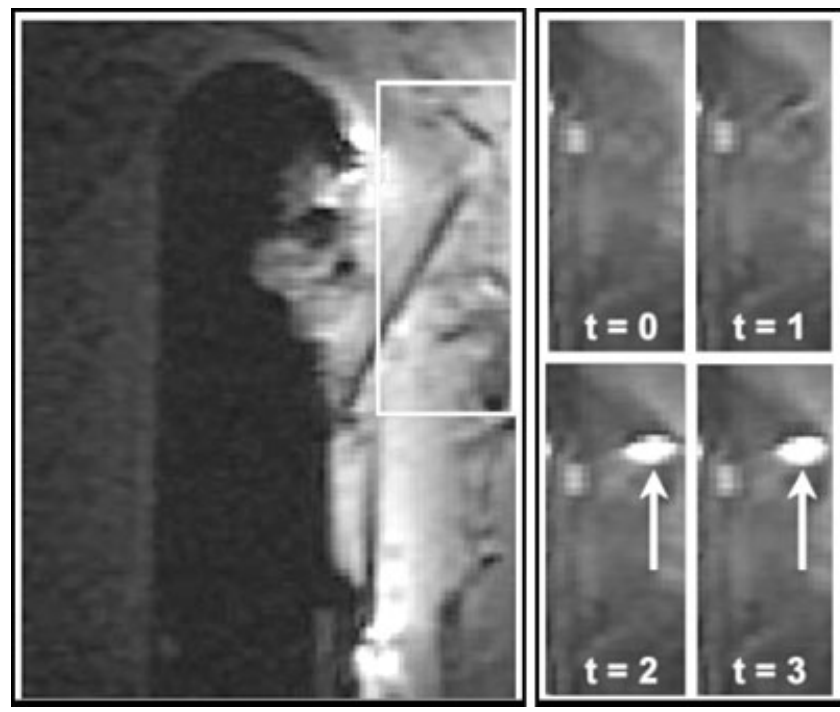

Fig. 3. Canine Single-Injection Trials: Injected contrast solution accumulating at the needle tip. $0.3 \mathrm{ml}$ of $30 \mathrm{mM} \mathrm{Gd}$-DTPA solution was injected over $5 \mathrm{sec}$ through the $18-\mathrm{G}$ canula. The solution is visible as a single bolus at the needle tip (arrows). Times are given in seconds.

therapeutic agent to the entire gland. Therefore, we examined the feasibility of covering large regions of tissue in the prostate by performing multiple injections. The eight injections performed in the first canine were all targeted within two axial planes; the first five injections were performed in one plane and the last
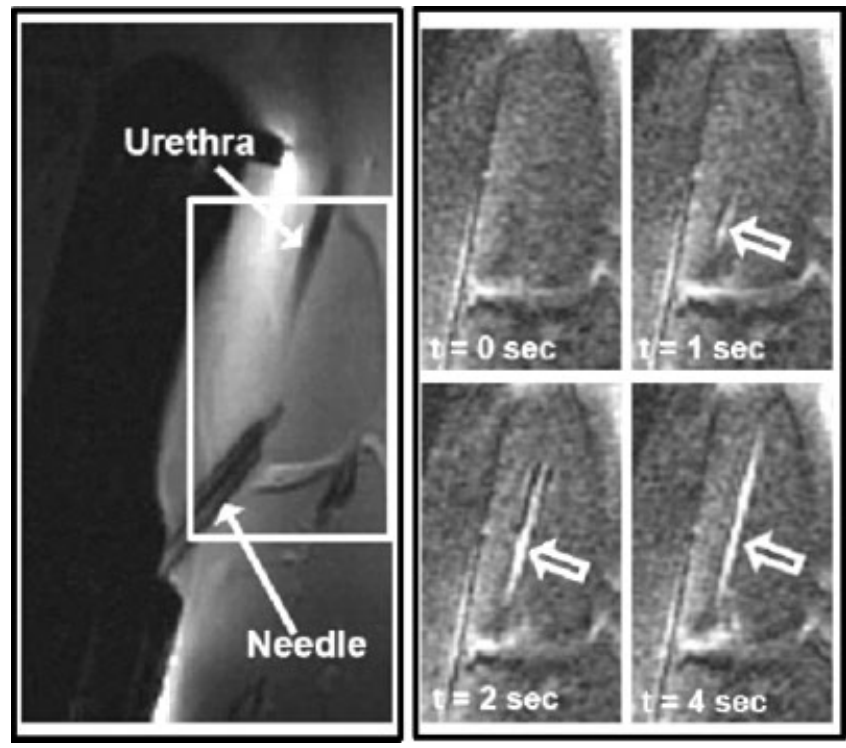

Fig. 4. Canine Single-Injection Trials: Injected contrast solution tracking along the intraprostatic urethra. $0.3 \mathrm{ml}$ of the Gd-DTPA solution was injected over $5 \mathrm{sec}$ through the 0.018 -inch diameter nitinol needle. Rather than accumulating at the needle tip, the solution tracks up the intraprostatic urethra (open arrows). 


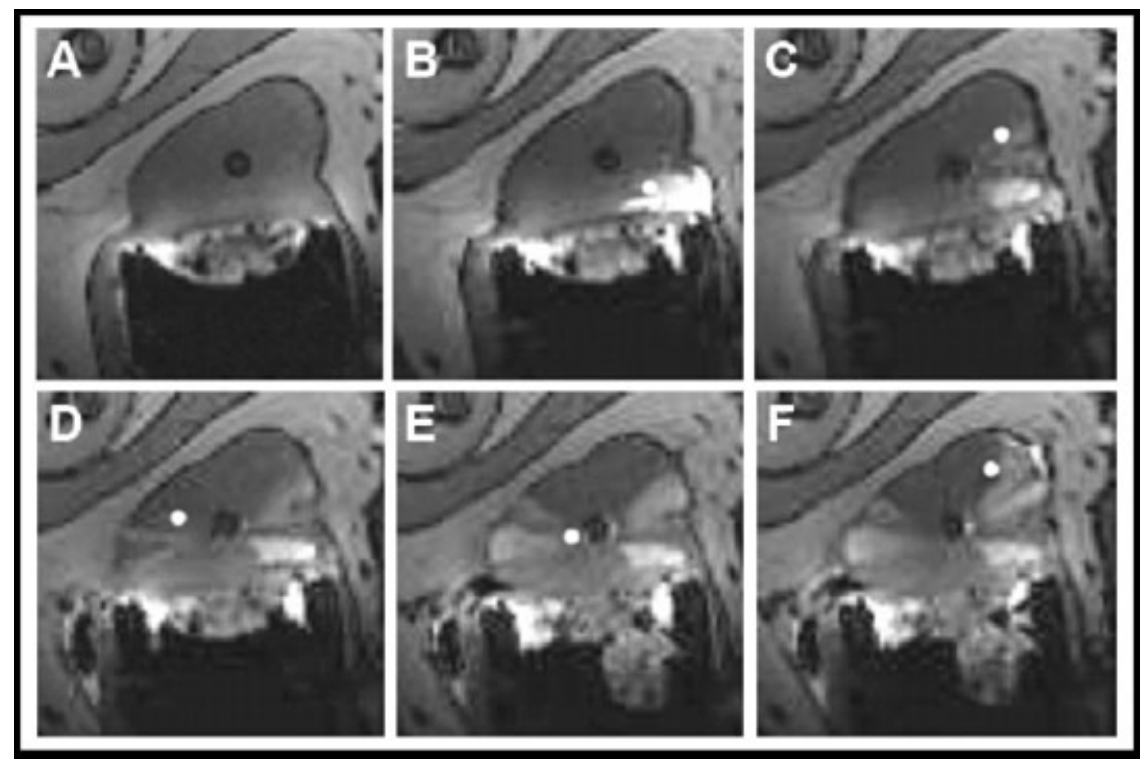

Fig. 5. Canine Multiple-Injection Trials: Incomplete tissue enhancement. Five contrast boluses (all $0.3 \mathrm{ml}$ except for the fourth, which was $0.6 \mathrm{ml}$ ) were injected over $30 \mathrm{sec}$ ( $60 \mathrm{sec}$ for the fourth bolus). Injection sites are indicated by the white circles. Despite the large number of injections, a majority of the tissue in this image plane is not enhanced.

three in another. The results of the first six injections are shown in Figure 5. Note that despite the large number of injections performed within this image slice, there are sizable regions of tissue that show no contrast enhancement. However, the results of the last three injections, shown in Figure 6, are significantly different. Despite the low number of injections, almost all of the tissue within the image slice shows enhancement.

\section{Gadolinium Preinjections}

In the second canine, the utility of performing gadolinium solution preinjections, before the therapeutic agent is injected, was examined. Injections at two sites within the canine prostate are demonstrated. Following accurate placement of the needle at the first target site (Fig. 7A), the gadolinium solution was injected. At this site, gadolinium tracks to the urethra, showing that subsequent ethanol injection may injure this tissue (Fig. 7B). No ethanol was injected and the tissue was spared. Therefore, no tissue damage, only minor bleeding at the needle track was seen on gross pathology (Fig. 7C). At the second injection site, the needle was accurately placed (Fig. 7D) and gadolinium injected. The gadolinium stayed more localized within the prostate tissue and away from the urethra (Fig. 7E). This injection site was deemed safe and subsequently, $0.2 \mathrm{ml}$ of ethanol was injected. The region of tissue damage, as seen on gross pathology (Fig. 7F), correlates well with the distribution of gadolinium on the T1-weighted images.

\section{Human Versus Canine Prostate}

Although the canine prostate is a widely used model of the human prostate, injection experiments reveal differences in tissue structure that affect

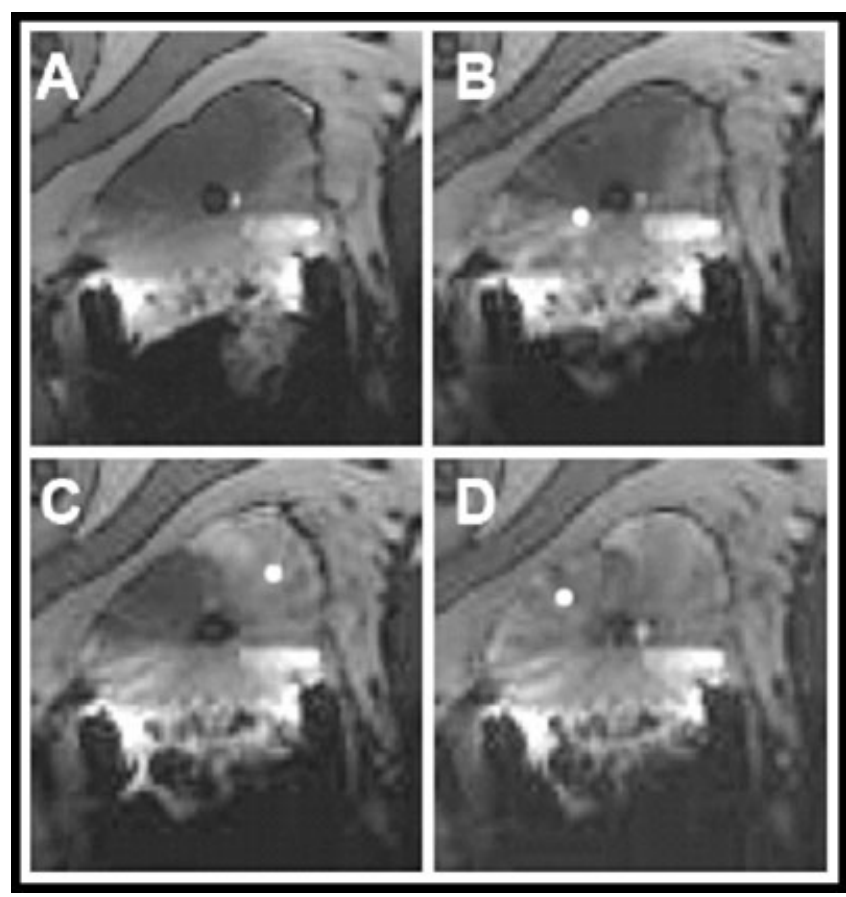

Fig. 6. Canine Multiple-InjectionTrials: Complete tissue enhancement. Three boluses of Gd-DTPA solution $(0.15,0.3$, and $0.3 \mathrm{ml}$, respectively) were injected over 5 sec each. Despite the low number of injections, strong enhancement of the whole tissue plane is achieved. 


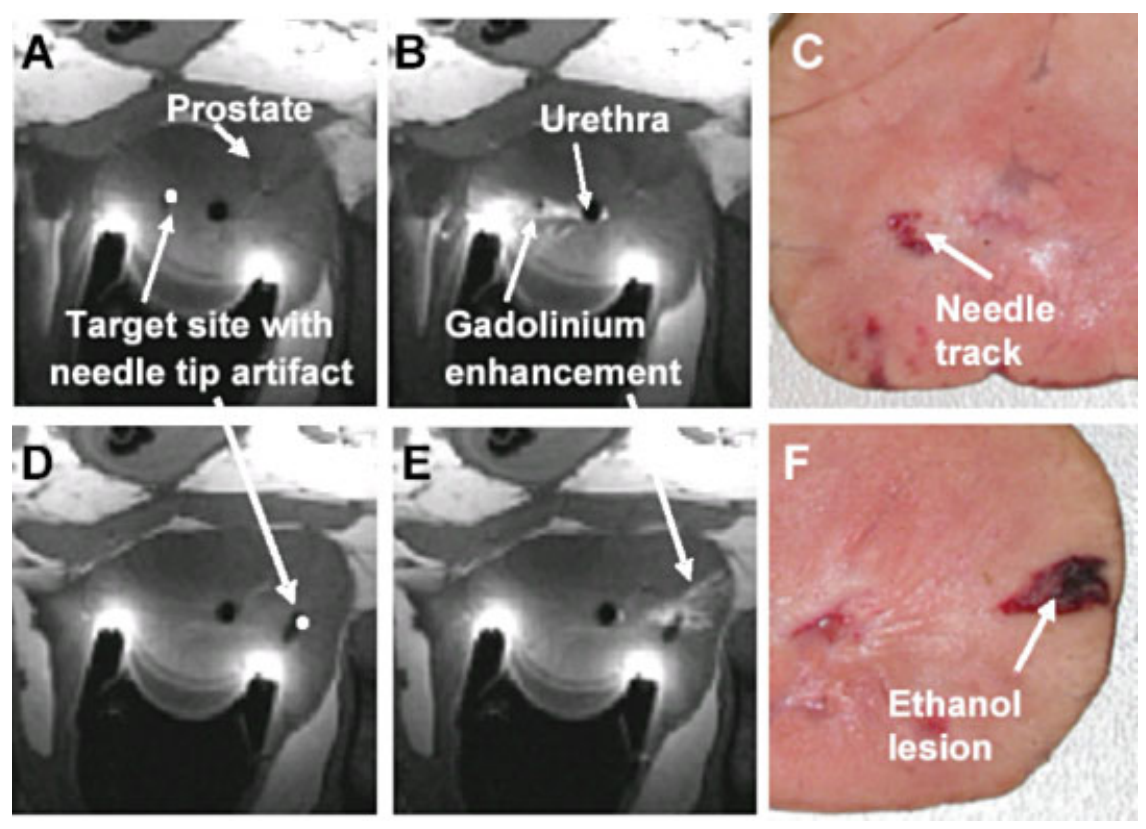

Fig. 7. Canine Gadolinium PreinjectionTrials: Gd-DTPA preinjections can be used to predict drug distribution patterns. Panel A:The injection needle was accurately placed at the first injection site. Panel B: Gadolinium solution injected at this site tracked to the urethra. Therefore, no ethanol was injected here. Panel C: No tissue necrosis is visible on gross pathology (only minor bleeding at the needle tip site). Panel D:The injection needle was accurately placed at the second injection site. Panel E: Gadolinium solution injected here stayed localized.Therefore, $0.2 \mathrm{ml}$ of ethanol was injected. Panel F:Tissue necrosis is visible on gross pathology and correlates well with the gadolinium injection pattern. [Color figure can be viewed in the online issue, which is available at www.interscience. wiley.com.]

intraparenchymal liquid distribution. From an axial perspective, the canine prostate has a wedge-shaped pattern of glandular units separated by connective tissue, similar in structure to an orange. The human prostate has a more complex structure, with ducts that run from the periphery of the gland and spiral towards the urethra on the posterior side. In general, the canine prostate is symmetric with respect to the anterior/ posterior axis, whereas the human prostate is not. A comparison of human and canine injections is shown in Figure 8. Figure $8 \mathrm{~A}$ shows an anterior injection pattern, and Figure $8 \mathrm{~B} / \mathrm{C}$ show posterior injection patterns in human prostates. Note that Figure 8D shows several almost identical looking wedge shaped patterns from multiple injections in the canine prostate. In the canine model injecting into the anterior or posterior portion of the gland gives the same distribution, whereas for human prostates injecting in the anterior portion of the gland gives a different distribution than the posterior portion. These results are consistent with the anatomical structural differences between canine and human prostate, showing that tissue structure is one predictor of injectant distribution.

\section{MR Versus Histology Correlation for Human Prostate Injections}

A 0.018-inch diameter needle made from nitinol hypotubing was placed in an excised human cadaveric prostate and a volume of T1-weighted gradient echo images were collected (Fig. 9, first column). Following injection of $0.3 \mathrm{ml}$ of Trypan blue tissue dye mixed with $30 \mathrm{mM}$ Gd-DTPA, a second set of axial T1-weighted images was acquired, allowing for clear visualization of the injected solution (Fig. 9, second column). Tissue sections corresponding to the imaged planes are shown in Figure 9, third column. Note that there is good agreement between the injectant dispersion patterns as seen on MR images with the histology pictures taken afterwards. This is evidence that MR guided injections can in fact be used as an accurate method of visualizing injectant dispersions.

\section{Fixed Versus Fresh Human Prostate Injections}

All injections into the fixed prostate required significantly higher pressure to infuse the tissue, in fact the pressure required was so large that it fell outside the injector range of allowable fluid pressures. Therefore, we had to deliver the injections by hand. The flow rate was timed to be kept as close as possible to $0.1 \mathrm{ml} / \mathrm{sec}$.

Figure 10 shows that the three formalin-fixed prostate injections showed very poor tissue coverage compared to the fresh prostates. Contrast enhancement was limited to a vector-like pattern directly into the urethra. Chemical fixation causes greatly increased tissue pressure, which would explain the very limited tissue 

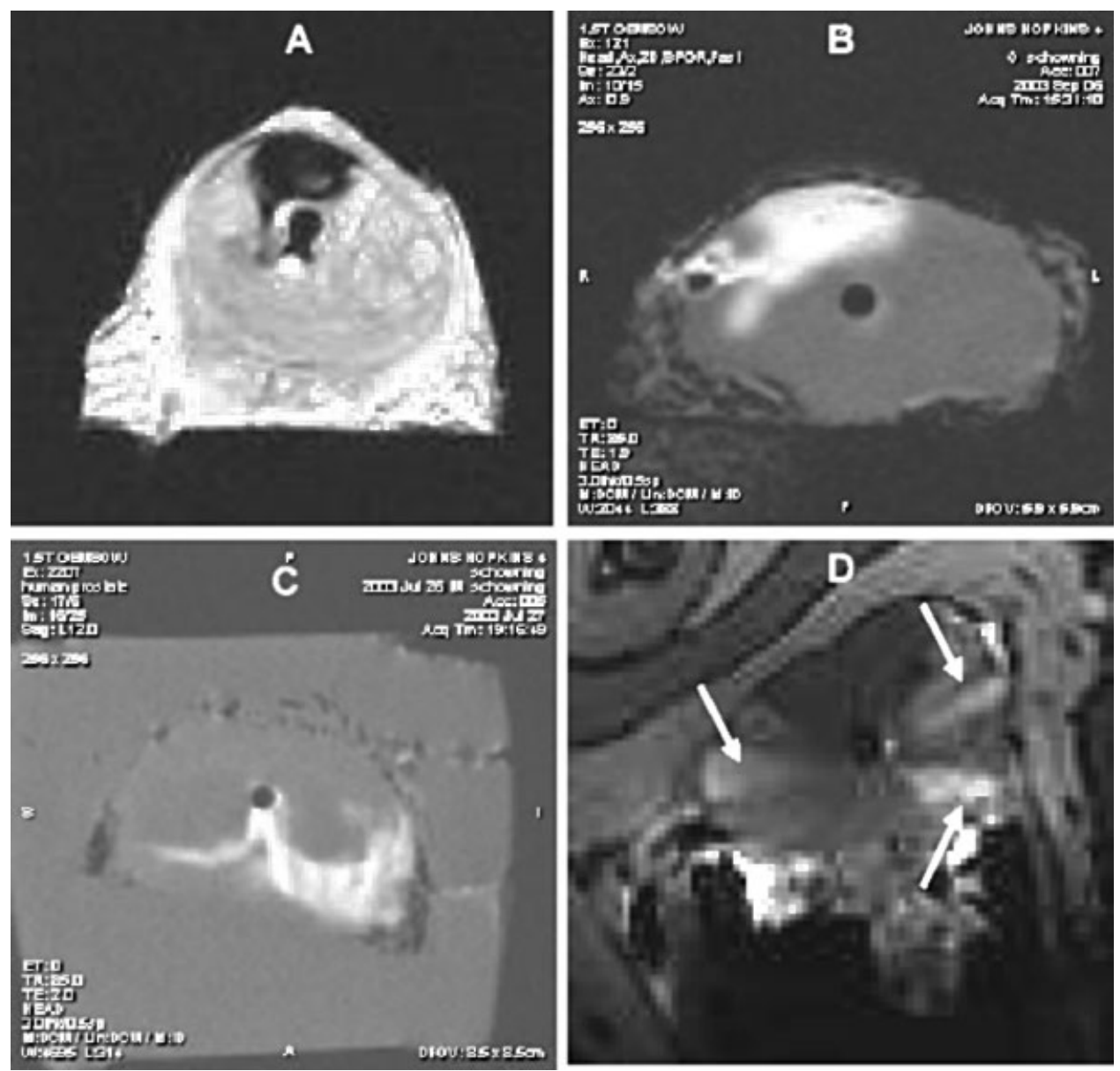

Fig. 8. Canine versus Human Injection Trials: Canine injections display uniformity whereas human injections show variance. Panels A-C: Human prostate injections at various points in the axial plane. Note the different shape of each distribution. Panel A is a T2 weighted image in which contrast appears dark. Panel D: Canine prostate injections showing multiple injections in the same axial plane (arrows mark injection locations). Note the uniform wedge-shaped distributions.

distribution and higher fluid pressures required to infiltrate the gland.

\section{Real-Time Human Prostate Injection Images}

Using the real-time MR sequence described in the Methods, a "movie" comprised of 1-sec snapshots of each injection was captured. Figure 11 shows an example with a T2-weighted baseline image and several snapshots after the injection at varying time intervals. From this set of images, the contrast can be seen accumulating at the needle tip and then gradually flowing around the periphery of the TZ near the capsule towards the PZ. The baseline image shows good contrast between the TZ and PZ as a guide to distinguishing these two different anatomical areas. Note that coverage in the $\mathrm{TZ}$ proper is poor, and that most of the enhancement is seen in the capsular area, progressing towards the PZ. This was a consistent theme in our experiments; a TZ target covers only a small portion of the TZ and most of the agent flows to the PZ.

\section{Diffusion-Weighted Imaging and Injection Correlation}

Using the multiple spin echo T2 diffusion-weighted sequence described previously, a diffusion map of the axial plane of each human prostate was acquired. Figure 11B shows the sum of the ADC and the exponentially weighted ADC as a combination image. Note the striking similarity between the tissue structure shown in the baseline image (Fig. 11A) and the diffusion image. As shown in the real-time data in Figure 11, the injectant tends to distribute according to local tissue structure, and this tissue structure has a correlation with the diffusion-weighted data.

\section{Leakage in the Human Prostate}

There was a correlation found between the injection site and the probability of leakage. Leakage is defined as contrast enhancement seen on MR in the urethra or beyond the prostatic capsule (see Fig. 4 for an example). 

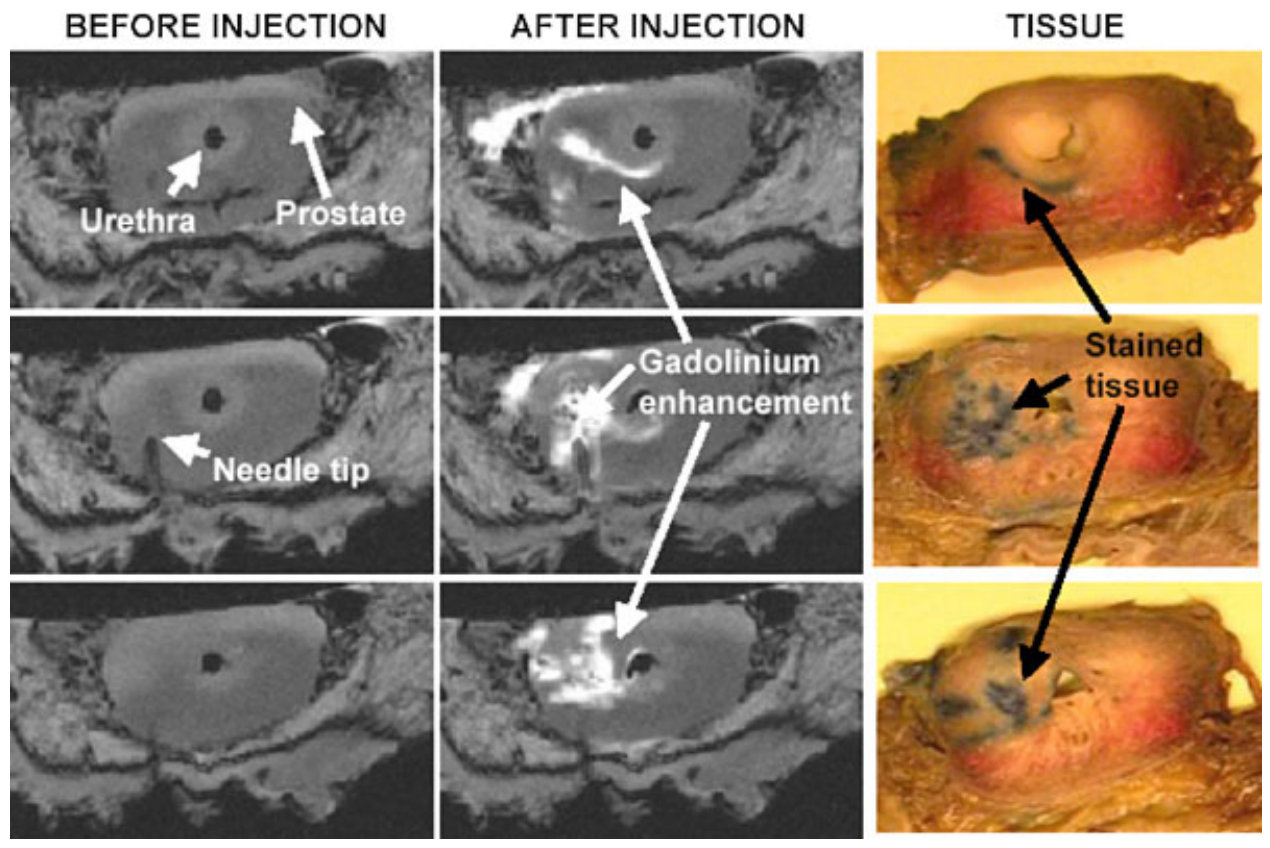

Fig. 9. Human Injection Trials: Histology and magnetic resonance monitoring of distributions show close agreement. First column: A 0.018 inch diameter nitinol injection needle was placed by hand into the prostate, and $\mathrm{Tl}$-weighted gradient echo images were acquired. Second column: Following injection of $0.3 \mathrm{ml}$ of $30 \mathrm{mMGd}$-DTPA mixed withTrypan blue tissue dye (over $30 \mathrm{sec}$ ), a second set of TI-weighted gradient echo images were acquired. Enhancement due to the gadolinium solution is clearly visible. Third column: Blue stained tissue. Seen in gross tissue sections of the prostate, corresponds well with the enhancement seen in MR images. [Color figure can be viewed in the online issue, which is available at $w w w$.interscience. wiley.com.]

Table I shows a breakdown of the injections that leaked. A couple of observations arose from this data: (1) PZ injections are more likely to leak via the urethra than $\mathrm{TZ}$ injections; and (2) TZ injections are more likely to show leakage through the prostatic capsule. Overall, $100 \%$ of PZ injections showed some form of leakage, whereas only $50 \%$ of the TZ targets showed leakage. Note that the distances measured between PZ/TZ and leakage points (urethra or capsule) lead to somewhat surprising observations. The PZ-urethral distance was statistically higher than the PZ-capsule distance, yet in spite of this
PZ-urethral leaks were much more common. On the other hand, TZ-capsule distances averaged less than TZ-urethral distances, and capsular leaks were found to be more common. This suggests that bulk flow in the PZ tends to be of a vector type nature that dominates in one direction along the ducts. One possible explanation for this phenomenon is based on the anatomical structure of the duct coverage in the PZ. As the ducts converge at the urethra, they become larger, and thus can facilitate higher bulk flow in that direction. This may create a tissue/fluid pressure gradient that
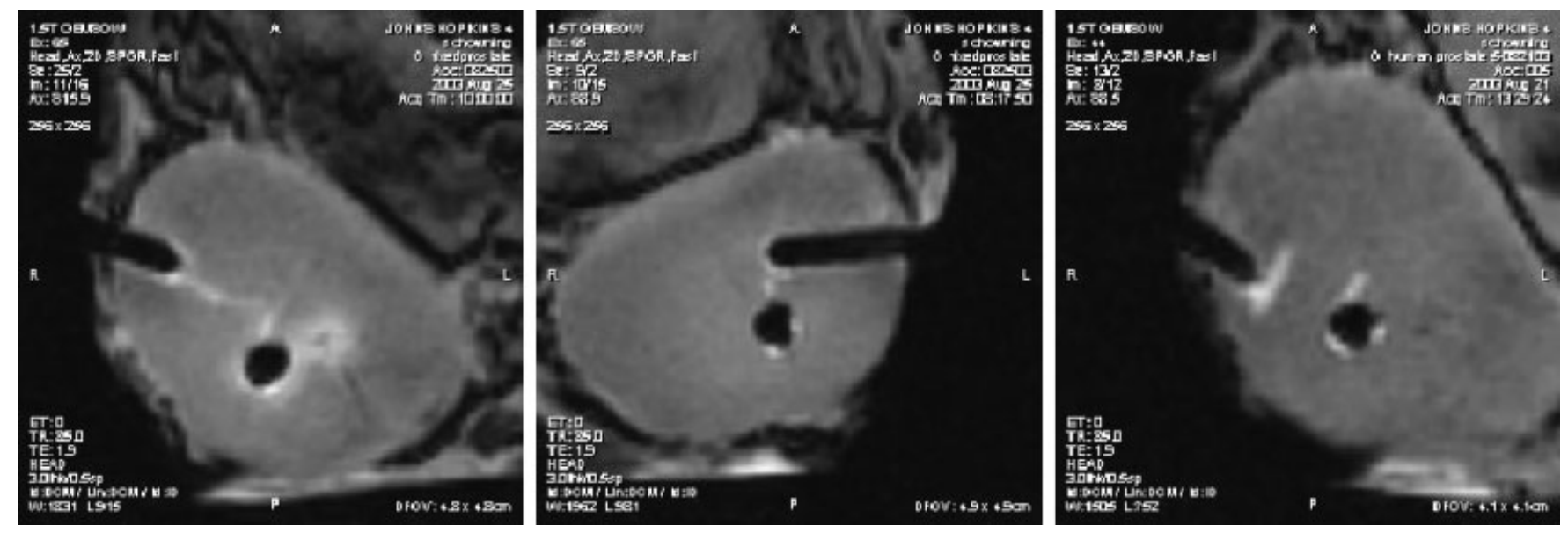

Fig. 10. Human InjectionTrials:Three injections in a formalin-fixed specimen. Note the extremely poor coverage of the tissue. 

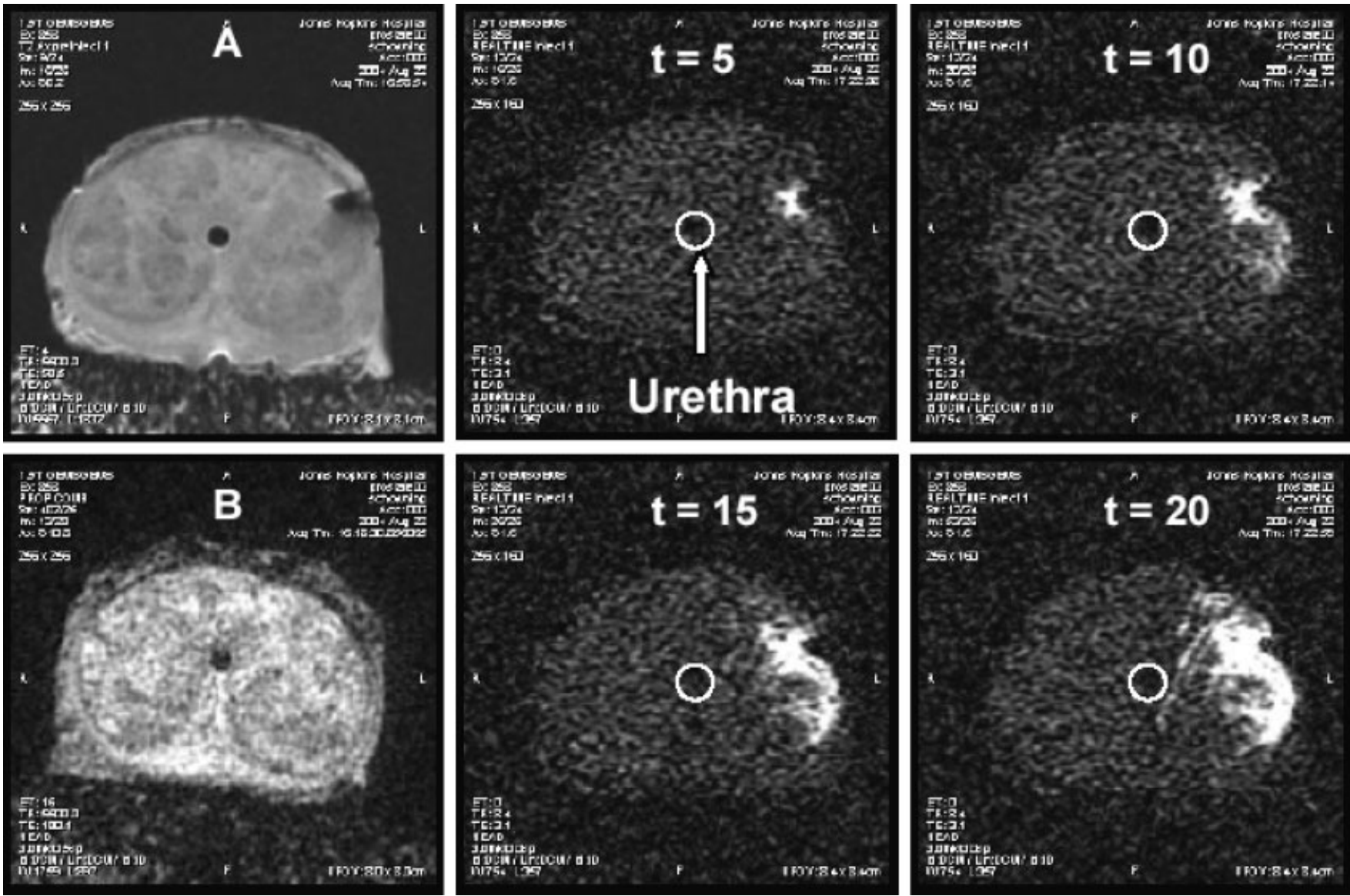

Fig. II. Human Injection Trials: Diffusion-weighted and real-time MR images. Panel A:T2 weighted baseline image. Panel B:T2 diffusion weighted image (DWI). Other panels show real time capture of injection (times are in seconds). Urethra is outlined by the white circles. Note the enlarged prostate, poor coverage of transition zone (TZ), and motion of contrast towards peripheral zone.

encourages flow in the direction of the urethra and away from the capsule and lateral portions of the TZ.

\section{Distribution Planes in the Human Prostate}

To get a better understanding of how drug distribution may differ in the three primary anatomical planes (superior/inferior, anterior/posterior, and medial/ sagittal), we acquired images of all three major planes after each injection. In the first set of experiments in which both flow rate and total volume injected were held constant, the dispersion of contrast relative to the three major axes was measured and is shown in Figure 12. Note that for constant flow rate and volume, the dispersion amongst the axes showed little variation. For the second set of trials in which volume was increased by $100 \%$ with a fixed flow rate, the average dispersion in the axial plane was relatively unchanged, however the dispersion along the longitudinal axis (superior to inferior direction) was increased substantially. This further demonstrates the lack of correlation between axial plane coverage and total volume injected (compare Figs. 5 and 6). In the third set of trials with varying flow rates and fixed total volume, the dispersion data sets were not statistically different (save for a slight statistically significant variance in the anterior/ posterior distribution), although it is noteworthy that the coverage was actually reduced in the increased flow rate.

\section{DISCUSSION}

Intraprostatic injections, using dehydrated ethanol, are currently being investigated as a minimally invasive treatment for benign prostatic hypertrophy (BPH) [20], which has a prevalence of $50 \%$ in men over 50 and greater than $80 \%$ in men over 80 [21]. When injected into the prostate, ethanol induces cell lysis and coagulation necrosis of arteries and veins, resulting in tissue necrosis and subsequent shrinkage of the prostate (reducing the obstructive symptoms caused by $\mathrm{BPH})$. Others have hypothesized that alcohol injections reduce BPH symptoms by abolishing prostate constriction (due to destruction of $\alpha$-adrenergic receptors 


\section{TABLE I. Leakage Data in Ex Vivo Human Prostates}

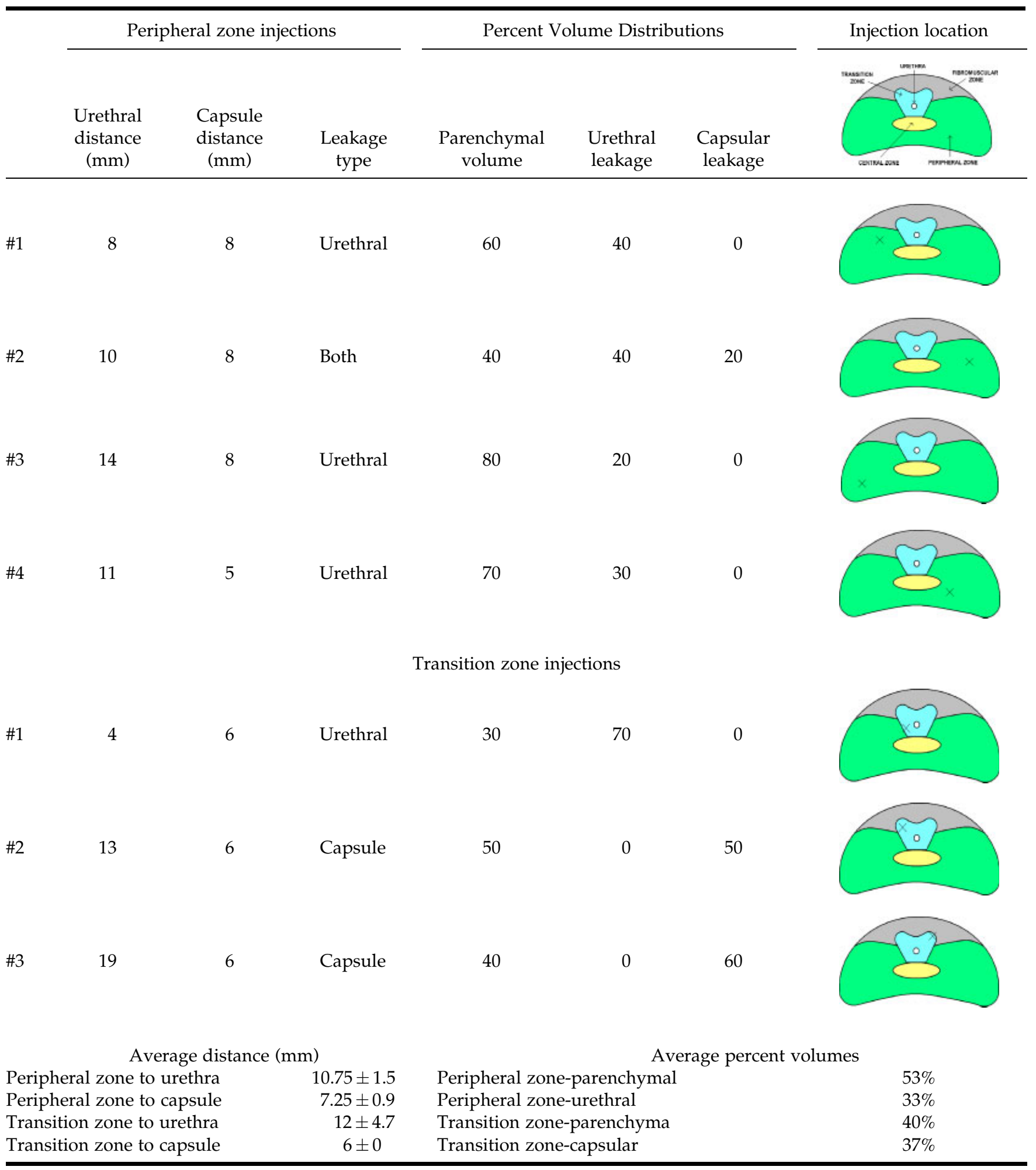

in the tissue) [22]. However, side effects that have plagued this treatment are inadvertent damage to the external urethral sphincter, which is important for urinary continence and stricture of the urethra [23].
This damage is caused by leakage of injected ethanol into the urethra and periurethral tissue, which then damages the endothelium and muscular sphincter, resulting in stricture and/or incontinence. In light of 


\section{Human Injectant Dispersion Along 3 Anatomical Axes}

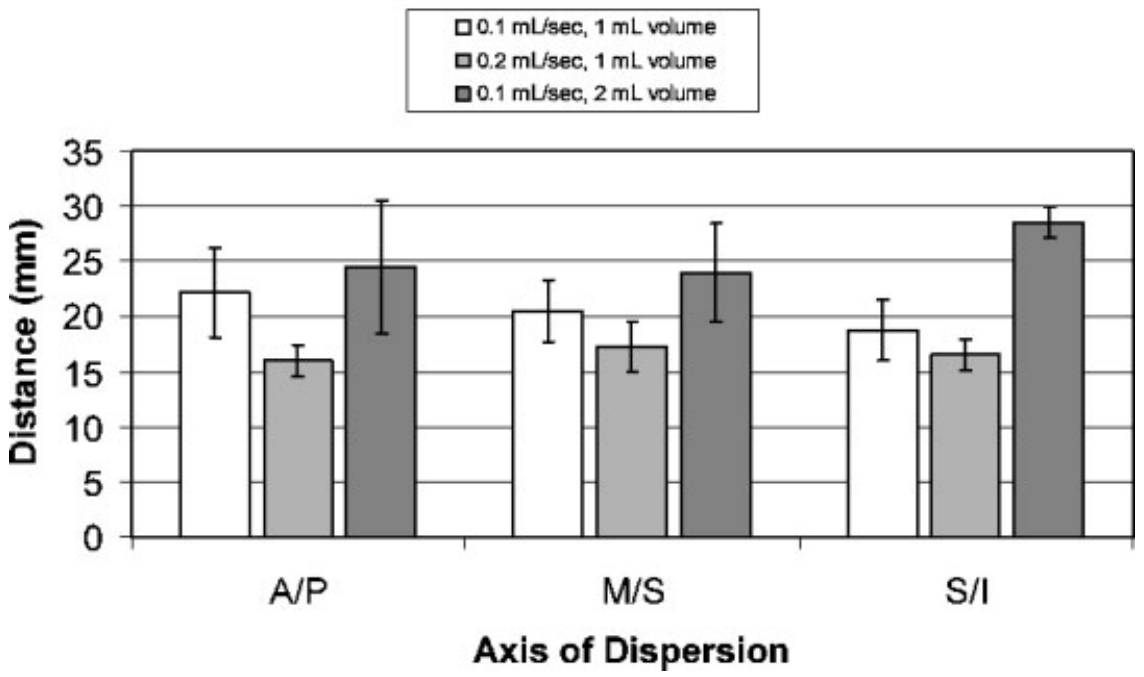

Fig. 12. Human InjectionTrials: Injectant dispersion along each anatomical axis. $A / P=$ anterior/posterior (fibromuscular zone to rectal wall), $\mathrm{M} / \mathrm{S}=$ medial/sagittal (urethra to capsule), $\mathrm{S} / \mathrm{I}=$ superior/inferior (base to apex).

the results seen in this study, the frequent side effects following intraprostatic ethanol injections are not surprising. When performing transrectal intraprostatic injections, we observed significant leakage of contrast solution in 8 of 11 cases in the canine model. A simplistic model in which the injected agent stays localized at the needle tip is insufficient.

MRI may be useful for improving the efficacy and safety of these injections. First, through the use of realtime projection imaging (Figs. 1-4), it is possible to determine during the injection whether the agent is staying localized at the target or rather, if it is leaking into surrounding tissue. Therefore, failed injections could be stopped early, conserving drug and preventing damage to surrounding tissues. When a gadolinium preinjection is delivered before the drug, this approach allows for immediate determination of whether the injection site is safe and therefore, whether the therapeutic agent should be subsequently injected. Second, if more precise visualization of the injected agent is desired, T1-weighted images can be collected to visualize the three-dimensional distribution of the injected solution within the tissue (Figs. 7 and 8).

Clearly, intraprostratic injections performed without direct imaging confirmation may not actually deliver the therapeutic agent to a desired target. Given the limited number of injections performed in this study, it is difficult to suggest a definitive solution to this problem. Nevertheless, several important mechanisms can be hypothesized based on these preliminary results.

First, injection rate may play an important role in determining the distribution of injected solutions. Fast injection through the $18-\mathrm{G}$ needle (Fig. 3) and the hypotubing needles (Figs. 4 and 7) did not suffer from "back-leakage" along the needle track. However, another fast injection through the $18-\mathrm{G}$ needle $(0.3 \mathrm{ml}$ in $5 \mathrm{sec}$ ) similar to Figure 4 did show some back-leakage along the needle (results not shown). In these cases, the velocity with which the solution exits the needle is high (velocity is higher when using the hypotubing needle because of its small cross-sectional area). The resulting forward momentum may help to force the solution into the tissue, resisting capillary forces that would draw the liquid out along the needle path. While this mechanism seems plausible, high injection rates in the liver have been shown to increase leakage rates [24].

Second, while high injection rate appears to reduce back-leakage, it is also correlated with increased leakage through the internal structures of the prostate (as in Fig. 4, where solution tracked along the urethra). If the solution is forced into the tissue, it will follow a low resistance path, which in the prostate leads to the urethra (the ductal structure of the canine and human prostate is directed toward the intraprostatic urethra). This is concerning in that high concentrations of a drug, such as injected ethanol, may cause damage to the urethra and associated sphincters and therefore lead to either stricture or incontinence.

Third, as already alluded to, the underlying tissue structure has a very significant impact on the distribution of an injected liquid agent. This effect is evident in the canine prostate, which has a separated wedge-like structure (similar to an orange cut in cross-section). In Figures 5 and 6, this structure is clear after contrast 
injection. Similarly, the injections performed in the excised cadaveric prostates follow the tissue structure of the human prostate. For example, in Figure 8C, contrast tracks along the course of secretary ducts within the peripheral gland, which flow toward the midline of the gland and the urethra [25].

Other factors which are likely to be important include the viscosity of the injected solution (highly viscous solutions flow, and therefore leak, less easily), the size of the injection needle (independent from injection rate, smaller needles may reduce damage to the tissue structure, and therefore reduce leakage), and the volume of injected solution (smaller volume injections will result in lower pressures and therefore, reduced leakage flow). Further work is warranted to clarify the relative important of each of these factors.

The present results showed only modest success in reliably covering large regions of tissue with a small number of injections. Our limited data suggest that total volume injected has a poor correlation with tissue coverage. Indeed, the canine prostate experiments showed greater coverage when less total volume was injected and more total injection sites were used. Further work needs to be done to elucidate whether or not this is a consistent phenomenon. While global enhancement was achieved in Figure 6, it is important to note that this enhancement was limited to the $3 \mathrm{~mm}$ thick slice shown (some enhancement of the neighboring slices was also seen). To cover the entire prostate, better strategies-such as needles with multiple tips or side ports-may be necessary.

To help predict the tissue distribution of a therapeutic agent, a contrast preinjection strategy has been proposed and demonstrated (Fig. 7). While this technique appears attractive, it relies on important assumptions. First, the distribution pattern of the therapeutic agent must be similar to that of the preinjection; otherwise, the preinjection will not yield useful information. In the example using ethanol presented here, it appears that the injected ethanol has a more restricted tissue distribution than the $30 \mathrm{mM}$ Gd-DTPA solution (compare Figure 7E, F). Therefore, just because the GdDTPA solution tracked to the urethra in the first injection (Fig. 7B), we cannot be sure that the ethanol would have matched that distribution. Unequal distribution will likely be a problem for many agents, unless the preinjected agent can match the molecular size and chemical characteristics of the therapeutic solution. However, as the initial distribution pattern appears to be determined largely by bulk fluid flow, matching characteristics such as viscosity may be sufficient.

One key finding to future research methodology in this area is that formalin-fixed human prostates give profoundly different injection patterns than fresh pros- tates. Since fresh prostates stored in isosaline solution are assumed to be a better model of in vivo prostate injections, it is important that all ex vivo modeling be done on fresh not fixed specimens. Fresh ex vivo prostate injections may differ from in vivo results, due to many variables such as altered tissue compliance, perfusion washout due to blood flow, and physiological parameters not active in fixed specimens. Despite the limitations of ex vivo work, we believe this is a fundamental step on the road to in vivo testing. More work is planned in the future with in vivo studies to determine if injection patterns remain similar.

The leakage data in Table I show that PZ injections have an extremely high probability of urethral leakage. In fact, every single injection in the PZ showed some urethral leak. Depending on the particular clinical application this can be acceptable or not. For example, in ethanol ablation therapy, leakage in the urethra would be highly undesirable, due to possible damage at the urethral sphincter. On the other hand, in the case of an adenovirus vector used for prostate cancer treatment, urethral leakage is not nearly as troublesome. The nerve plexus that controls erectile function is located outside the prostatic capsule, and some drug agents such as certain chemotherapeutics may harm these nerves; under this scenario minimizing capsular leakage may take precedence over urethral leakage. Capsular leakage was found to be not as common as urethral leakage, although TZ targets do face a higher probability of capsular leak. These observations suggest that if avoiding urethral leak is a primary goal, then PZ injections should be avoided, whereas if the clinician is more concerned with capsular leaks and can afford to risk urethral leakages, then the TZ is an optimal injection target.

A preliminary injection model can be based on the data in Figures 11 and 12. Generally, our experiments showed that TZ targets showed reduced bulk flow compared to the PZ targets, which has a good correlation with the diffusion-weighted image presented in Figure 11. In addition other studies have shown that the TZ has a lower ADC on average compared to PZ tissue [26], giving further credence to the hypothesis that tissue structure and diffusion-weighted maps are one predictor of injectant distribution. This suggests that therapeutic targets in the $\mathrm{TZ}$ may require multiple injection sites and/or a larger total volume injected. Note that Figure $8 \mathrm{C}$ shows that a PZ injection to one side of the prostate can result in coverage of both PZ lobes. In our experiments, we found that it was rare for TZ injections to penetrate bilaterally. This suggests that bilateral coverage of $\mathrm{PZ}$ targets may be achieved with a unilateral injection site, whereas bilateral $\mathrm{TZ}$ coverage probably requires bilateral injection sites. It is noted that larger total volume injected has relatively little 
effect on axial plane dispersion but does have a sizable impact on longitudinal (coronal and sagittal plane) dispersion (Fig. 12).

One final interesting observation regarding $\mathrm{TZ}$ versus PZ injections is that a sufficiently large volume delivered to the $\mathrm{TZ}$ can in some cases penetrate a good portion of the ipsilateral PZ, whereas larger volumes delivered to the $\mathrm{PZ}$ rarely cover the $\mathrm{TZ}$ and the excess volume tends to either leak out the urethra or flow to the bilateral PZ via the major ducts that converge with the urethra at the verumontanum and at distributed sites in the periurethral region. See Figures 8 and 9 for examples of PZ and TZ distributions. Figure 9 shows an example of a TZ injection, whereas Figure $8 \mathrm{C}$ shows a PZ injection. More work needs to be done to have sufficient statistical certainty of this phenomenon, but if this holds up to further scrutiny it could be extremely valuable as an injection-planning tool.

\section{CONCLUSION}

Although prostate injections are a desirable minimally invasive procedure for some pathologies, this modality is still under utilized due to failure modes that can lead to complications, as well as uncertainty regarding optimal injection techniques. This study attempts to address some of these issues using the advantages of MR imaging that elude traditional TRUS imaging, such as excellent soft tissue contrast. Leakage modes were demonstrated, including capsular back leakage along the needle path and urethral leakage for PZ targets. Drug agent distribution was analyzed in three anatomical planes, and a preliminary guide to injection planning was developed based on that data. Dynamic imaging during the injection as well as T1weighted imaging after the injection allows for monitoring of the solution's distribution within and around the prostate. Primarily, we have found that intraprostatic injections often follow a complex distribution within and around the prostate; leakage both within and around the prostate was common. MR visualization of injected agents may allow for prediction and monitoring of drug distributions, improving efficacy, and reducing treatment side effects. One strategy for predicting drug distribution patterns, the use of a contrast preinjection was suggested and demonstrated. Taking into account the unique properties of the prostate zones, as well as the prostate structure as a whole, can serve as a preliminary guide to planning injections. Further studies, taking advantage of the ability of MRI to reveal tissue micro- and superstructure, may allow for improved prediction of drug distribution and therefore optimization of therapeutic agent delivery.

\section{REFERENCES}

1. Livraghi T, Festi D, Monti F, Salmi A, Velotti C. US-guided percutaneous alcohol injection of small hepatic and abdominal tumors. Radiology 1986;161(2):309-312.

2. Fujimoto T. The experimental and clinical studies of percutaneous ethanol injection therapy (PEIT) under ultrasonography for small hepatocellular carcinoma. Acta Hepatolog Jap 1988; 29:52.

3. Solbiati L, Giangrande A, De Pra L, Belloti E, Cantu P, Ravetto C. Percutaneous ethanol injection of parathyroid tumors under US guidance: Treatment for secondary hyperparathyroidism. Radiology 1985;155(3):607-610.

4. Takeda S, Michigishi T, Takazakura E. Successful ultrasonically guided percutaneous ethanol injection for secondary hyperparathyroidism. Nephron 1992;62(1):100-103.

5. Goya N, Ishikawa N, Ito F, Kobayashi C, Tomizawa Y, Toma H. Transurethral ethanol injection therapy for prostatic hyperplasia: 3 year results. J Urol 2004;172(3):1017-1020.

6. Susil RC, Krieger A, Derbyshire JA, Tanacs A, Whitcomb LL, Fichtinger G, Atalar E. System for MR image-guided prostate interventions: Canine study. Radiology 2003;228(3):886-894.

7. Plante MK, Gross AL, Kliment J, Kida M, Zvara P. Intraprostatic ethanol chemoablation via transurethral and transperineal injection. BJU Int 2003;91(1):94-98.

8. Nelson PS. Identifying immunotherapeutic targets for prostate carcinoma through the analysis of gene expression profiles. Ann N Y Acad Sci 2002;975:232-246.

9. DeWeese TL, van der Poel H, Li S, Mikhak B, Drew R, Goemann M, Hamper U, DeJong R, Detorie N, Rodriguez R. A phase I trial of CV706, a replication competent, PSA selective oncolytic adenovirus, for the treatment of locally recurrent prostate cancer following radiation therapy. Cancer Res 2001;61(20):7464-7472.

10. Nemunaitis J. Selective replicating viral vectors: Potential for use in cancer gene therapy. Bio Drugs 2003;17(4):251-262.

11. Mercatante DR, Mohler JL, Kole R. Cellular response to an antisense-mediated shift of Bcl-x pre-mRNA splicing and antineoplastic agents. J Biol Chem 2002;277(51):49374-49382.

12. Trudel S, Trachtenberg J, Toi A, Sweet J, Hua Li Z, Jewett M, Tshilias J, Zhuang LH, Hitt M, Wan Y. A phase I trial of adenovector-mediated delivery of interleukin-2 (AdIL-2) in high-risk localized prostate cancer. Cancer Gene Ther 2003; 10(10):755-763.

13. Li S, Simons J, Detorie N, O’Rourke B, Hamper U, DeWeese TL. Dosimetric and technical considerations for interstitial adenoviral gene therapy as applied to prostate cancer. Int J Radiat Oncol Biol Phys 2003;55(1):204-214.

14. Bhutani MS. Endoscopic ultrasound guided antitumor therapy. Endoscopy 2003;35(8):S54-S56.

15. Dudouet P, Portalez D, Lhez JM, Elman B, Larroque JM, Bachaud JM, Redon A, Ribot JF. Trans-rectal ultrasonography (TRUS) with lipiodol injection for localization of the prostatic apex before radiotherapy planning. Radiother Oncol 2001;61(2):135141.

16. Rauh G, Pieczek A, Irwin W, Schainfeld R, Isner JM. In vivo analysis of intramuscular gene transfer in human subjects studied by on-line ultrasound imaging. Hum Gene Ther 2001; 12(12):1543-1549.

17. Yu KK, Hricak H. Imaging prostate cancer. Radiol Clin North Am 2000;38(1):59-85,viii.

18. Savoca G, De Stefani S, Gattucio I, Paolinelli D, Stacul F, Belgrano E. Percutaneous ethanol injection of the prostate as minimally 
invasive treatment for benign prostatic hyperplasia: Preliminary report. Eur Urol 2001;40(5):504-508.

19. Krieger A, Susil RC, Menard C, Coleman JA, Fichtinger G, Atalar E, Whitcomb LL. Design of a novel MRI compatible manipulator for image guided prostate interventions. IEEE Trans Biomed Eng 2005;52(2):306-313.

20. Ditrolio J, Patel P, Watson RA, Irwin RJ. Chemo-ablation of the prostate with dehydrated alcohol for the treatment of prostatic obstruction. J Urol 2002;167(5):2100-2103; discussion 2103-21034.

21. McConnell JD. Benign prostatic hyperplasia: diagnosis and treatment (clinical practice guideline). Rockville, MD: Agency for Health Care Policy and Research, Public Health Service, U.S. Department of Health and Human Services; 1994. Report \# AHCPR 94.0582.

22. Zlotta AR, Raviv G, Peny MO, Noel JC, Haot J, Schulman CC. Possible mechanisms of action of transurethral needle ablation of the prostate on benign prostatic hyperplasia symptoms: A neurohistochemical study. J Urol 1997;157(3):894-899.

23. Littrup PJ, Lee F, Borlaza GS, Sacknoff EJ, Torp-Pedersen S, Gray JM. Percutaneous ablation of canine prostate using transrectal ultrasound guidance. Absolute ethanol and Nd:YAG laser. Invest Radiol 1988;23(10):734-739.

24. Alexander AL, Barrette TR, Unger EC. Magnetic resonance guidance of percutaneous ethanol injection in liver. Acad Radiol 1996;3(1):18-25.

25. Walsh PC, editor. Campbell's urology. Philadelphia: W.B. Saunders; 2002.

26. Sato $C$, Naganawa $S$, Nakamura $T$, Kumada $H$, Miura $S$, Takizawa O, Ishigaki T. Differentiation of noncancerous tissue and cancer lesions by apparent diffusion coefficient values in transition and peripheral zones of the prostate. J Magn Reson Imaging 2005;21(3):258-262. 